COPING AFTER INFANT LOSS

\title{
A Synthesis of Coping Experiences after Infant Death
}

\author{
Deborah Stiffler PhD, RN, CNM \\ Associate Professor, Science of Nursing Care \\ Indiana University School of Nursing \\ 600 Barnhill Drive (new address after 02/27/2016) \\ Indianapolis, IN \\ dstiffle@iu.edu Phone 317-274-3288 Fax 317-317-274-2411
}

\author{
Nicole Birch \\ BSN Honors Student \\ Indiana University School of Nursing \\ Indianapolis, IN \\ nbirch@indiana.edu \\ Hailey Campbell \\ BSN Honors Student \\ Indiana University School of Nursing \\ Indianapolis, IN \\ handrzej@iupui.edu
}

\author{
Deborah Cullen EdD \\ Professor, Science of Nursing Care \\ Indiana University School of Nursing \\ Indianapolis, IN \\ Clinical Fellow, Joanna Briggs Institute \\ Adelaide, Australia
}

dcullen@iu.edu Phone 317-278-3926 Fax 317-317-274-2411

The authors have no conflict of interest.

This is the author's manuscript of the article published in final edited form as:

Stiffler, D., Birch, N., Campbell, H., \& Cullen, D. (2017). A Synthesis of Coping Experiences After Infant Death.

Holistic Nursing Practice, 31(2), 118. https://doi.org/10.1097/HNP.0000000000000199 
COPING AFTER INFANT LOSS

\title{
A Synthesis of Coping Experiences after Infant Death
}

\begin{abstract}
The purpose of this article was to use meta-analysis of qualitative research data to understand parental coping and healing after the loss of an infant. The authors found that parents cope more effectively with the death of their infant when they have intergenerational support in the form of family being present and acknowledge the death, perform immediate tasks, and provide helpful information. Nurses should be vigilant to assure parents receive "memories" of their infant after an in-hospital death. Knowledge of the coping process can assist nurses and clinicians to better care and support parents following an infant death and in turn facilitate the healing process.
\end{abstract}

Keywords: coping, infant or child, death, loss, bereavement, parents, SIDS, meta-synthesis 
COPING AFTER INFANT LOSS

\section{INTRODUCTION}

The loss of an infant is one of the most intense emotional experiences a parent can endure. Worldwide in 2015, 4.5 million infant deaths occurred within the first year of life and accounted for $75 \%$ of all deaths in children under the age of 5 years old. ${ }^{1}$ This is significant because it determines where health care needs are the greatest and it gives focus on what can be done to reduce infant and childhood mortality rates. The death of an infant is a life altering event for those involved in the care of the infant. An estimated $19 \%$ of the adult population will experience the death of a child by miscarriage, stillbirth, or other natural causes. ${ }^{2}$ Lifelong grief exists for those who lose an infant. Understanding a family's grieving process may benefit nurses and clinicians in developing effective ways of assisting the family to heal from the trauma of an infant death. ${ }^{3}$

There is a dearth of knowledge regarding how parents and intergenerational family members may seek and receive counseling services after an infant death. However, there is quantitative data about memory making as a way of facilitating the immediate grieving and coping processes. According to Butler and colleagues, although almost all parents wanted hand or foot prints and photos of their infant, only $61.9 \%$ actually received them. ${ }^{4}$ Additionally, only $76.2 \%$ of parents who wanted their infant's hospital bracelet and $85 \%$ of parents who wanted a lock of hair actually received these physical memories from their healthcare team when the infant loss occurred in a hospital setting. ${ }^{4}$

Families have reported difficulty with acknowledging the reality of an infant death and subsequent coping. Butler and colleagues reported that parental grief was acknowledged as more intense and overwhelming than other forms of grief because parents not only lose a child, but also the part of themselves invested in the child and any hopes and dreams for the future. ${ }^{4}$ The 
COPING AFTER INFANT LOSS

intergenerational bond between parents and their children is one that is irreplaceable and therefore it is very difficult to overcome the loss of this bond. Since the bereavement process and coping occurs after this intense loss, research studies may provide insight to specific and successful experiences for families moving through the grief process.

Relatively few nursing interventions have been identified to support parents in their individual grieving processes as well as inform coping strategies for best clinical practices. In a qualitative study, Heidari and Norouzadeh addressed family-centered supportive nursing interventions for the intensive care. ${ }^{5}$ Qualitative research may address coping and grieving to illuminate new evidence about the emotional needs and psychological impacts of losing an infant. Research may also guide nurses and healthcare personnel in new ways to affect for healing and bereavement.

An essential aspect of qualitative research is the patient perspective. Qualitative studies can be enlightening about the human experience and may advance knowledge regarding the inclusion of evidence based practices for families overcoming the grief and heartache of infant death. Qualitative research improves understanding of the phenomena being studied and is considered more illustrative rather than a priori. ${ }^{7}$ Gathering information from the patient's perspective provides the opportunity for discovery and analysis of common themes among parents who have experienced an infant loss. Combining results from multiple qualitative studies creates data patterns that ultimately allow meta-summary. ${ }^{6}$ In comparison to single study methods, synthesis of interpretive patterns and themes from multiple qualitative studies enhances comprehension of the research. Meta-synthesis is a research method and technique for drawing conclusions from analogous studies with an interpretative focus. ${ }^{7}$ 
COPING AFTER INFANT LOSS

The purpose of this study was to search the literature, collect qualitative research studies, interpret the findings, and use meta-analysis of qualitative research data to understand parental coping and healing after the loss of an infant. . The specific review question is, What are parents' coping experiences and processes following an infant death?

\section{METHODS}

Articles addressing infant loss or death were sought from a traditional search of the literature. The search included English language published studies from 2005-2015. Search terms used were infant or child, death, loss, bereavement, parents, coping, SIDS, qualitative, experiences or phenomenology. The Web of Science, CINAHL, PsycINFO and PubMed were searched and articles that met inclusion criteria were retrieved for review of the abstract.

\section{Inclusion Criteria}

Only qualitative articles related to coping experiences of parents affected by infant death were qualified for inclusion in this study. Infants were age 30 days to one year old. The participants were either primary parents to the deceased infant or extended family members involved in the coping and grieving process; this included studies of mothers, fathers, or grandparents. Moreover, in studies that included children as well as infants - only infant data was considered. In total, 395 articles were identified (Figure 1).

\section{Exclusion Criteria}

The 392 articles were excluded because the main focus was not on the individual or family experience of coping or dealing with the loss following an infant death. Stillborn or spontaneous abortion loss was not included. Neonatal, infants less than 30 days old, preemies, or infants older than one year were not included. Articles that described cultural customs for grieving from Africa, Asia, or South America duplicate articles, articles older than 10 years, 
COPING AFTER INFANT LOSS

dissertations, and review papers were excluded. Articles regarding the nurses' or clinicians' viewpoint were not used for meta-summary (see Figure 1 for search strategy).

\section{Types of Studies}

This qualitative review consisted of articles that discussed the parent and family perspective of coping with the aftermath of infant loss. Any qualitative study with a focus on post-infant death coping and grieving processes qualified for inclusion. The methods of these studies ranged from phenomenology to interviews. Quantitative studies and systematic reviews were not included. Outcome measures were not significant for qualitative studies because their findings emanate from experiences and were not predefined. The final papers were assessed for validity by a primary and secondary reviewer via standardized critical appraisal instruments from the Joanna Briggs Institute. Three articles met inclusion criteria through the search process and are overviewed in Table 1.

The Qualitative and Assessment and Review Instrument (QARI) from the Joanna Briggs Institute (JBI), available through OVID Tools, was used to assist with management of the data. ${ }^{8,9}$ The software assists with accumulation of data from the participants' lived experiences into the categories and themes identified that were sifted and scrutinized. This organizational computerbased tool, was used to meta-aggregate qualitative the data.

Data extraction of the findings was carried out to determine coping strategies after an infant death. The data included specific details about intergenerational support, interrelationship support, and lasting emotional impressions following an infant death. Coping processes and themes were examined. Representative illustrations from the study allowed for data to be categorized for each finding. Credibility was determined for each finding within the QARI process. Categories were then accumulated into like themes with meta-aggregation. 
COPING AFTER INFANT LOSS

\section{RESULTS}

A total of twelve findings were identified from the three studies and these findings were formulated into nine categories. Each finding was thematically categorized by the researchers and tested for representativeness. From the nine categories, meta-synthesis resulted in two synthesized findings. Table 2 shows the nine thematic categories

We identified that the influence of living children and grandparents were significant sources of intergenerational support. Conversely there was a lack of support between the primary parents leading to incomplete coping within the relationship or marriage. Furthermore, lasting emotional impressions indicating unresolved grieving were acknowledged as a recurrent theme among individuals affected by the loss of an infant. Table 3 reveals the final meta-synthesis.

\section{Effective Coping}

This qualitative review found that parents who effectively cope with the death of their infant will continue the bond with the deceased child, have differences in the way they manage their emotions about the loss, and have intergenerational support in the form of family being present, acknowledging the death, performing immediate tasks, and providing helpful information. Continuing the bond can be a form of both effective and ineffective coping. For example, in Table 2, Violet (a pseudonym) discussed how a physical symbol, the duplicated statue, "appeared to unite them by providing a common bond and meaning, something that both

of them could hold onto." ${ }^{10}$ Coping is a very individualized process that requires parents to, at varying times, be close to the memory of their lost infant or to distance themselves from the pain of the loss. One of the interviews conducted by Hooghe and colleagues, ${ }^{3}$ demonstrated that sometimes the spouse needed to stand at a relative distance while the other spouse coped in his 
COPING AFTER INFANT LOSS

or her own individual way. Additionally, support for the notion that managing emotions differently between the mother and father is a beneficial coping mechanism comes from White and colleagues. ${ }^{11}$ White and colleagues noted that a major component of intergenerational support was the couple's own parents being accepting of the differing pathways of coping that were taken by each parent. "Those who experienced this [intergenerational] supportive presence felt both understood and cared for" which contributed to their ability to effectively cope with the loss of an infant. ${ }^{11(p p ~ 194)}$ Much is discussed about effective coping as a result of intergenerational support. Intergenerational support helps grieving parents by alleviating certain pressures on the parents immediately following the infant death. For example, intergenerational family members are able to help with funeral services and arrangements, providing helpful information and personal experiences, and by acknowledging the parent's grief while being present for them as well. ${ }^{11}$

\section{Ineffective Coping}

The second major finding from this qualitative review consisted of several mechanisms that contributed to ineffective coping following infant death including continuing the bond, parents' ambivalence to their own mortality, protection from vulnerable emotions, and lack of support and unskilled support from family members. Initially, this study found that although continuing the bond provided positive coping experiences in some circumstances, it also provided negative coping in other circumstances. For example, in the article "Mothers Continuing Bonds and Ambivalence to Personal Mortality after the Death of their Child - an interpretive phenomenological analysis", one mother visited her daughter's grave every day. ${ }^{10}$ This mother felt the need to continue caring for her daughter as she had done when she was alive and was unable to give up her role as a mother which inhibited this mother from healing. In 
COPING AFTER INFANT LOSS

addition, this article spoke to the idea of ambivalence to personal mortality following infant death. This was demonstrated when the participants stated that their own deaths was welcomed in order to end their current suffering, or as a way of reuniting them with their lost child. ${ }^{10}$ Protecting one's self from painful emotions has the potential to be effective; however, it becomes ineffective when these protective barriers prevent one from working through the emotions in order to heal. Hooghe and colleagues ${ }^{3}$ discussed this notion by saying that the parent's emotional core is surrounded by a thick crust that they only want to penetrate under their own will and certain circumstances. The crust blocks the parents from feeling the emotions caused by the loss and ultimately deters their coping process. Finally, White and colleagues ${ }^{11}$ also found that a lack of intergenerational support for grieving parents lead to ineffective and incomplete coping. Two of the topics discussed were unskilled support, family members not knowing or understanding what the parent's needed, and no support at all. For example, the most lost and distraught mothers indicated they received no support from other family members and described their difficulty functioning after their infant loss. ${ }^{11}$

\section{DISCUSSION}

There is a broad range of other studies and popular societal behaviors and beliefs that validate the meta-synthesis results. Although not all of these studies utilize qualitative methods, they provide similar findings. In a study by Dyregrov and Dyregrov parental grief reactions were compared. ${ }^{12}$ It was found that the mothers tend to have more grief reactions immediately following the infant's death than the fathers based on multiple inventories that were collected. ${ }^{12}$ Women who have increased grief reactions closer in time to the death may be better able to confront and acknowledge their feelings and emotions. The man in the relationship feels the need to be strong immediately following the death as a means of support for his wife and family. ${ }^{12} \mathrm{~T}$ 
COPING AFTER INFANT LOSS

his prevents the fathers from being able to have adequate grief reactions early on and being able to work through the pain of losing a child. O'Leary and Warland ${ }^{13}$ also write about how men frequently feel that they cannot openly acknowledge their grief or mourn out in public. Instead men hold these emotions inside. Some men never have the chance to adequately grieve for their child.

Adequate time to grieve is essential to all family members. There is little understanding about the length or depth of the grief that the mother and father need, but it is known that support is needed for the family as failure to properly grieve for the loss of a child can be detrimental to the well-being of the family. ${ }^{13}$ Symptoms of Post-Traumatic Stress Disorder (PTSD) and longterm depression have been diagnosed in bereaved parents who have been unable to complete their grief or have had complicated grief processes. ${ }^{13}$

Furthermore, Krueger ${ }^{14}$ deduced that grief and mourning include not only the immediate family, but also the extended, intergenerational family members. The parental shock following an infant death can be so great that the parents are unable to complete tasks such as funeral arrangements and therefore must rely on family members for quick support and guidance. ${ }^{14}$ Krueger's findings correlate with White and colleagues' study in that intergenerational support is a significant necessity for healing in the immediate and long term coping process for parents. ${ }^{11,14}$ Rudd and D'Andrea agrees. ${ }^{15}$ In their study, they found that grieving parents had to have procedures and timelines "chunked" out for them in small increments or they could just not handle the responsibility. In the immediate 72 hours after the child's death came the autopsy, then interviews with detectives or police. In days 3-14 came the funeral planning and the expectation of the preliminary autopsy reports. If the parents had family members present to help with completing planning funerals and helping out at home, the tasks and timelines progressed 
COPING AFTER INFANT LOSS

more smoothly. After the funeral, the parents worked on the process of grief and their "new

normal." ${ }^{15}$ It wasn't until after the parents received the autopsy report and the cause-of-death for their child that the parent(s) talked about wanting to be with other who had experienced what they had experienced; those who had a child who had died of the same thing that their child had died from the same thing. ${ }^{15}$

According to $\mathrm{CNN}$ reporter, Madison Park, immediate conception or adoption of another child after an infant death is a means of ineffective coping. ${ }^{16}$ This concept, known as "replacement child," becomes a devastating myth to parents that they have the opportunity to replace the lost infant and thus alleviate all of their grief. ${ }^{16}$ This topic arose after John Travolta and his wife, Kelly Preston, conceived a child right around the one year mark of their 16 year old son's unexpected death. Park's findings support the idea that people are irreplaceable and that there is an instinctive need and desire to continue the bond with the deceased infant. If the parent(s) have not sufficiently grieved the loss of the previous child, the new child is at risk for significant psychopathology. If parents are trying to maintain a connection with the deceased child by preserving the space the child would have inhabited or try to create a relationship with the dead child through the new child, the parents should be referred for counselling. However, if the parents had always planned on a particular number of children and seem to be functioning normally, going on with their lives can be a sign of appropriate resolution of grief. ${ }^{17}$

\section{CLINICAL IMPLICATIONS FOR NURSES AND CLINICIANS}

Nurses interacting with families who have experienced infant death have the ability to assist the family and parents through the difficult situation. Curricula are available which include holistic approaches and spiritual care. ${ }^{18,19}$ Nursing interventions could include education for the parents and their extended families that addresses coping strategies and administering emotional 
COPING AFTER INFANT LOSS

coping assessments at regular intervals post infant death for those at risk for poor coping. Additionally, if the infant passes away in the hospital setting, nurses should be vigilant to assure parents receive "memories" of their infant. These memories would include hand and foot molds, a lock of the infant's hair, or their hospital ID band. Home visits may also be offered by nurses or social workers as needed. Follow up should continue over a period of time as necessary to meet the parent's individual needs as they cannot hear and absorb everything at one time. ${ }^{20}$

\section{Limitations}

Although qualitative studies provide valuable information about the lived experiences of individuals, the medical field is hesitant to accept this as a form of evidence based research. Qualitative studies are not generalizable to all people; however, their findings help us to understand how people react to their experiences and why they behave the way they do. The population size for this study was small and the sample size was small and not randomized. The sample was also purposively collected.

\section{CONCLUSIONS}

In conclusion, this meta-synthesis has shown that each parent affected by infant death faces complicated and idiosyncratic grieving processes. Parents deal with the pain of infant death work to confront their grief and subsequently reshape their lives without the infant. Parents are seldom given appropriate and adequate resources to overcome the life changing event of an infant loss.

Infant death is one of the most traumatic experiences a mother and father can endure. Given the magnitude of an infant death, there is inappropriate continuation of attention and support offered to families in the weeks and years following the death. Further qualitative meta- 
COPING AFTER INFANT LOSS

synthesized studies should focus on helping parents deal with the possibility of guilt, studying the effects of couple- and family- counseling, and the dispersion of grief resources after an infant death event.

\section{REFERENCES}

1. World Health Organization. (2015). Global Health Observatory (GHO) Data: Infant Mortality. Available at http://www.who.int/gho/child health/mortality/neonatal_infant text/en/ Accessed November 2, 2015.

2. Rudd, R. A phenomenological study of the professional support requirements and grief interventions to parents bereaved by an unexplained death at different time periods in the grief process. US, ProQuest Information \& Learning.2010.71;3963-3963.

3. Hooghe A, Neimeyer RA, Rober P. Cycling around an emotional core of sadness: emotion regulation in a couple after the loss of a child. Qualitative Heath Research.2012; 22(9): 12201231.

4. Butler A, Hall H, Willets G, Copnell B. Parents' experiences of healthcare provider actions when their child dies: An integrative review of the literature. Journal for Specialists in Pediatric Nursing. 2015;20(1):5-20.

5. Heidari MR, Norouzadeh R. Supporting families of dying patients in the intensive care units. Holistic Nursing Practice. 2014;28(5):316-322. 
COPING AFTER INFANT LOSS

6. Cullen D L, Stiffler D. (2009). Long-term oxygen therapy: review from the patient's perspective. Chronic Respiratory Disease.2009;6(3): 141-147.

7. Grove SK. Evidence synthesis and strategies for evidence-based practice. In Grove S, Burns N, Gray JR, eds. The Practice of Nursing Research $7^{\text {th }}$ ed. Missouri: Elsevier; 2013: 469-505.

8. Wolters Kluwer Health. February 11, 2013. Walters Kluwer Health helps healthcare Institutions become a JBI-endorsed evidence-based organization. Available at http://www.wolterskluwerhealth.com/News/Pages/Wolters-Kluwer-Health-Helps-Healthcare$\underline{\text { Institutions-Become-a-JBI-Endorsed-Evidence-Based-Organization.aspx }}$ Accessed January 16, 2016.

9. Joanna Briggs Institute. 2011. Qualitative Appraisal and Review Instrument (QARI) [computer software] http://joannabriggs.org

10. Harper M, O’Connor R, Dickson A, O’Carroll R. Mothers continuing bonds and ambivalence to personal mortality after the of their child- an interpretative phenomenological analysis. Psychology, Health \& Medicine. 2011;16(2): 203-214.

11. White DL, Walker AJ, Richard LN. Intergenerational Family Support Following Infant Death. International Journal of Aging \& Human Development. 2008; 67(3): 187-208. 
COPING AFTER INFANT LOSS

12. Dyregov A, Dyregrov K. Long-term impact of sudden infant death: a 12-to 15-year followup. Death Studies. 1999; 23(7): 635-661.

13. O'Leary J, Warland J. Untold stories of infant loss: the importance of contact with the baby for bereaved parents. J Fam Nurs. 2013;19(3):324-47. doi: 10.1177/1074840713495972. Epub $2013 \mathrm{Jul} 12$.

14. Krueger G. Meaning-making in the aftermath of sudden infant death syndrome. Nursing Inquiry.2006; 13(3):163-171.

15. Rudd R, D'Andrea L. Professional support requirements and grief interventions for parents bereaved by an unexplained death at different time periods in the grief process. International Journal of Emergency Mental Health and Human Resilience. 2013; 15(1), 51-68.

16. Park, M. (2010). Conceiving after loss: 'You can never replace a child.' CNN iReport. Available at http://www.cnn.com/2010/HEALTH/05/24/pregnancy.grief.loss/ Accessed Jan 16, 2016.

17. Grout LA, Romanoff BD. (2010). The myth of the replacement child: Parents"' stories and practices after perinatal death. Death Studies. 2010; 24(2), 93-113. doi:

$10.1080 / 074811800200595$

18. Glick, LH. Nurturing nursing students' sensitivity to spiritual are in a Jewish Israeli nursing program. Holistic Nursing Practice. 2012; 26(2):74-78. 
COPING AFTER INFANT LOSS

19. Tirgari B, Iranmanesh S, Ali Cheraghi M, Arefi A. Meaning of spiritual care: Iranian nurses' experiences. Holistic Nursing Practice. 2013; 27(4):199-206.

20. Palmer, PH. The psychosocial consequences of sudden infant death syndrome. US, ProQuest Information \& Learning. 1997; 57: 6587-6587.

\section{$\underline{\text { Tables and Figures }}$}

Figure 1: Search strategy for meta-synthesis

Table 1 Included Studies

Table 2 Thematic Categories

Table 3 Meta-synthesis 


\section{Figure 1: Search strategy for meta-synthesis}

PubMed Search

Total $=204$ Kept 8

Infant or child, Death or loss, SIDS, Qualitative or phenomenology or descriptive or grounded

Limiters:2005-2015, English, Duplicates

\section{CINAHL via EBSCO Search}

Total $=64$ Kept 10

Infant or Child, death or loss, SIDS, Qualitative or Phenomenology or Descriptive

Limiters:2005-2015, English, Duplicates

PsychInfo via EBSCO Search

Total $=59$ Kept 2

Infant or child, Death or loss, Qualitative or phenomenology or descriptive or grounded

Limiters:2005-2015, English, Dissertations, Duplicates
Excluded 7; Not qualitative research, not infant population, not related to research question

Kept 1 for background and related literature

Excluded $=9$; Neonatal or stillborn not infant; sleep death no focus on family, not grieving or coping, not related to research question

Kept 1

Excluded $=57$

Health care professional as population, miscarriage or stillborn loss, homicide, survey research, not related to research question

Kept 2

Excluded $=4$

Web of Science Search

Total $=68$ Kept 4

Infant or child, Death or loss, Qualitative or phenomenology or descriptive

Limiters:2005-2015, English, Nursing, Social issues, Social biomedical, Pediatrics/OB-GYN
Miscarriage or stillborn, duplicates, not related to research question 
Table 1 Included Studies

\begin{tabular}{|c|c|c|c|c|}
\hline Authors & Orientation & Context & Participants & $\begin{array}{l}\text { Focus of the } \\
\text { Study }\end{array}$ \\
\hline $\begin{array}{l}\text { Harper, M., R. } \\
\text { O'Connor et al. } \\
\text { "Mothers continuing } \\
\text { bonds and } \\
\text { ambivalence to } \\
\text { personal mortality } \\
\text { after the of their child- } \\
\text { An interpretative } \\
\text { phenomenological } \\
\text { analysis." Psychology, } \\
\text { Health \& Medicine } \\
\text { 2011; 16(2):203-214 }\end{array}$ & $\begin{array}{l}\text { Phenomenology: } \\
\text { guided interviews } \\
\text { were transcribed } \\
\text { then interpretive } \\
\text { phenomenological } \\
\text { analysis was used } \\
\text { over a } 5 \text { phase } \\
\text { cyclical process }\end{array}$ & $\begin{array}{l}\text { York, } \\
\text { UK }\end{array}$ & $\begin{array}{l}13 \text { bereaved } \\
\text { mothers from } \\
\text { The } \\
\text { Compassionate } \\
\text { Friends } \\
\text { International } \\
\text { Charity and } \\
\text { Support Group }\end{array}$ & $\begin{array}{l}\text { Explore how } \\
\text { bereaved } \\
\text { mothers } \\
\text { describe coping } \\
\text { with the death } \\
\text { of their child } \\
\text { and identify } \\
\text { adaptive and } \\
\text { maladaptive } \\
\text { coping } \\
\text { behaviors }\end{array}$ \\
\hline $\begin{array}{l}\text { Hooghe, A., R. A. } \\
\text { Neimeyer, et al. } \\
\text { "Cycling Around an } \\
\text { Emotional Core of } \\
\text { Sadness": Emotion } \\
\text { Regulation in a Couple } \\
\text { After the Loss of a } \\
\text { Child." Qualitative } \\
\text { Health Research 2012; } \\
\text { 22(9):1220-1231. }\end{array}$ & $\begin{array}{l}\text { Qualitative: guided } \\
\text { interviews and } \\
\text { written feedback } \\
\text { followed by an } \\
\text { intensive auditing } \\
\text { process }\end{array}$ & Belgium & $\begin{array}{l}20 \text { couples who } \\
\text { lost a child }\end{array}$ & $\begin{array}{l}\text { To better } \\
\text { understand the } \\
\text { oscillating } \\
\text { process of } \\
\text { confronting } \\
\text { and avoiding } \\
\text { the pain of } \\
\text { infant loss }\end{array}$ \\
\hline $\begin{array}{l}\text { White, D. L., A. J. } \\
\text { Walker, et al. } \\
\text { "Intergenerational } \\
\text { Family Support } \\
\text { Following Infant } \\
\text { Death.” International } \\
\text { Journal of Aging \& } \\
\text { Human Development } \\
\text { 2008; 67(3):187-208. }\end{array}$ & $\begin{array}{l}\text { Grounded theory: } \\
\text { structured, open- } \\
\text { ended interviews } \\
\text { with transcription, } \\
\text { axial coding, and } \\
\text { data analysis }\end{array}$ & $\begin{array}{l}\text { Oregon } \\
\text { and } \\
\text { Portland }\end{array}$ & $\begin{array}{l}21 \text { grandparents, } \\
19 \text { parents from } \\
10 \text { families }\end{array}$ & $\begin{array}{l}\text { Examine social } \\
\text { support } \\
\text { between } \\
\text { grandparents } \\
\text { and their adult } \\
\text { children in the } \\
\text { aftermath of } \\
\text { infant death }\end{array}$ \\
\hline
\end{tabular}


COPING AFTER INFANT LOSS

Table 2 Thematic Categories

\begin{tabular}{|c|c|c|}
\hline $\begin{array}{l}\text { Name of } \\
\text { First } \\
\text { Author }\end{array}$ & Thematic Category & Participants' Voice \\
\hline Harper, M. & $\begin{array}{l}\text { Category 1: } \\
\text { Continuing the bond } \\
\text { Category 2: } \\
\begin{array}{l}\text { Personal mortality } \\
\text { ambivalence }\end{array}\end{array}$ & $\begin{array}{l}\text { Category 1: } \\
\text { In Violet's case, a neighbor offered something to place } \\
\text { in the infant's coffin; "My neighbor...went next door } \\
\text { and brought in an Infant of Prague and it was a nice } \\
\text { thing, so we put it in his hand." Violet reported that she } \\
\text { had bought an identical duplicate item which she kept } \\
\text { on display in her home. (Harper, 2010). } \\
\text { Category 2: } \\
\text { "The difficulty was all of the, sort of, mundane things, } \\
\text { looking after the kids or whatever, when I just wanted to } \\
\text { go and curl up and cry." She felt obliged to fulfil her } \\
\text { parenting role, at the expense of her own need to grieve } \\
\text { (Harper et al., 2010, pg 209). }\end{array}$ \\
\hline Hoog & $\begin{array}{l}\text { Category 1: } \\
\text { Protection from } \\
\text { vulnerable emotions } \\
\frac{\text { Category 2: }}{\text { Differences in }} \\
\text { management of } \\
\text { personal grief } \\
\text { between parents }\end{array}$ & $\begin{array}{l}\text { Category 1: } \\
\text { "There is a core of great sadness, around which there is } \\
\text { a crust, which gets thicker every year" (Hooghe et al., } \\
\text { 2012). } \\
\text { Category 2: } \\
\text { "At times, [the mother of the deceased infant] uses } \\
\text { humor, some laughing [...] to create some distance for } \\
\text { herself" (Hooghe et al., 2012). }\end{array}$ \\
\hline $\begin{array}{l}\text { White, D. } \\
\text { L. }\end{array}$ & $\begin{array}{l}\text { Category 1: } \\
\text { Intergenerational } \\
\text { emotional support } \\
\text { and being present } \\
\text { Category 2: } \\
\text { Intergenerational } \\
\text { emotional support } \\
\text { and acknowledgment } \\
\text { Category 3: } \\
\text { Instrumental support }\end{array}$ & $\begin{array}{l}\text { Category 1: } \\
\text { "Her mother came down from [another state] and stayed } \\
\text { with us for like a week... She was good and I liked that } \\
\text { she took time out (White et al., 2008)." } \\
\text { Category 2: } \\
\text { "You know, it's funny when you say our families were } \\
\text { supportive. It's not as if they sought out, brought up the } \\
\text { topic, and continued to sort of nurse us along. From our } \\
\text { point of view, supportive was just saying, "we } \\
\text { understand and we're really sorry" (White et al., 2008)." } \\
\text { Category 3: }\end{array}$ \\
\hline
\end{tabular}


COPING AFTER INFANT LOSS

\begin{tabular}{|l|l|l|}
\hline $\begin{array}{l}\text { and performing } \\
\text { immediate tasks }\end{array}$ & $\begin{array}{l}\text { "She [mother] asked me if I would handle contacting the } \\
\text { funeral home and at least getting him moved from the } \\
\text { hospital to the funeral home. So I did that (White et al., } \\
\text { 2008)." } \\
\begin{array}{l}\text { Category 4: } \\
\text { Instrumental support } \\
\text { and information } \\
\text { Category 4: }\end{array}\end{array}$ & $\begin{array}{l}\text { "The kinds of suggestions I gave her were simply } \\
\text { sharing...so anything I said to her I reminded her it was } \\
\text { simply nothing out of my experience, certainly (White } \\
\text { et al., 2008)." }\end{array}$ \\
$\begin{array}{l}\text { Category 5: } \\
\text { unskilled support }\end{array}$ & $\begin{array}{l}\text { Category 5: } \\
\text { "I would say that both grandfathers were just totally lost } \\
\text { as far as what to say, what to do... [this is] just } \\
\text { something that life doesn't prepare you for, you don't } \\
\text { get classes on it in school) White et al., 2008)." }\end{array}$ \\
\hline
\end{tabular}


COPING AFTER INFANT LOSS

Table 3 Meta-synthesis

\begin{tabular}{|c|c|c|}
\hline Meta-synthesized Finding & Thematic Categories & Illustration \\
\hline 1. Effective coping & $\begin{array}{l}\text { 1. Continuing the bond } \\
\text { 2. Differences in management } \\
\text { of personal grief between } \\
\text { parents } \\
\text { 3. Intergenerational emotional } \\
\text { support and being present and } \\
\text { acknowledging the death } \\
\text { 4. Instrumental support and } \\
\text { performing immediate tasks } \\
\text { and providing information }\end{array}$ & $\begin{array}{l}\text { "The item had been chosen by } \\
\text { her son and therefore } \\
\text { represented an emotional } \\
\text { response from him which } \\
\text { Donna coveted as a symbol of } \\
\text { her son's love for her" } \\
\text { (Harper et al., 2010) } \\
\text { "Sometimes it was easier to } \\
\text { talk about the pain of the loss } \\
\text { in ways that did not explicitly } \\
\text { verbalize it. Instead, } \\
\text { metaphorical language or } \\
\text { stories were used to talk about } \\
\text { the child" (Hooghe et al., } \\
\text { 2012). } \\
\text { "Being present at the time of } \\
\text { great sorrow included both } \\
\text { emotional and physical } \\
\text { appearance" (White et al., } \\
\text { 2008). } \\
\text { "Grandparents provided } \\
\text { substantial assistance in } \\
\text { making the } \\
\text { arrangements...including } \\
\text { contacting the funeral home, } \\
\text { locating cemetery plots, and } \\
\text { assisting their adult children } \\
\text { in making a variety of } \\
\text { decisions" (White et al., } \\
\text { 2008). }\end{array}$ \\
\hline 2. Ineffective coping & 1. Continuing the bond & $\begin{array}{l}\text { "Helen expressed the need to } \\
\text { hold on to her son's physical } \\
\text { remains, telling how she had } \\
\text { carried her son's ashes around } \\
\text { in a bag. She described this } \\
\text { behavior herself as 'crazy"” }\end{array}$ \\
\hline
\end{tabular}


COPING AFTER INFANT LOSS

\begin{tabular}{|c|c|c|}
\hline & $\begin{array}{l}\text { 2. Ambivalence to their own } \\
\text { mortality } \\
\text { 3. Excessive protection from } \\
\text { vulnerable emotions } \\
\text { 4. Lack of support and } \\
\text { unskilled support }\end{array}$ & $\begin{array}{l}\text { (Harper et al., 2010). } \\
\text { 2. "Norman (husband) and I } \\
\text { said early on, if we didn't } \\
\text { have any children, I would } \\
\text { not be here...the boys are here } \\
\text { so we have no choice" } \\
\text { (Harper et al., 2010). } \\
\text { 3. "The crust had a protective } \\
\text { value because it shielded the } \\
\text { emotional core" (Hooghe et } \\
\text { al., 2012) } \\
\text { 4. "Frequently, nonsupport } \\
\text { was attributed to clumsiness } \\
\text { in offering support and a lack } \\
\text { of knowledge or } \\
\text { understanding of what was } \\
\text { needed" (White et al., 2008). }\end{array}$ \\
\hline
\end{tabular}

